\title{
Energy Efficiency in Developing Countries: Roles for Sector Regulators
}

\author{
By Sanford V. Berg ${ }^{1}$ \\ Emeritus Professor--Economics, and \\ Director of Water Studies, Public Utility Research Center, University of Florida \\ Revised, October 1, 2015-Forthcoming Energy for Sustainable Development
}

\begin{abstract}
In addition to implementing Renewable Energy (RE) initiatives, sector regulators also have roles to play in promoting Energy Efficiency since EE can be expanded via utility actions (incentivized and monitored by the regulator) and actions by other agencies. The former include reduced line losses, improvements in load patterns and system reliability, decision-relevant customer billing information, energy audits, and smart grids. The adequacy and cost-effectiveness of utility programs clearly falls under regulatory oversight. Other agencies set appliance standards and provide government financial support. The sector regulator must then factor in the interdependencies among EE programs when determining the cost-effectiveness of utility-based programs. EE promotes energy conservation, so such programs impact utility revenues and costs (directly through changes in consumption and production patterns and in program costs). These impacts mean that the energy sector regulator can promote or block some EE initiatives carried out by the electric utilities.
\end{abstract}

Keywords: Energy Efficiency, Regulation, Public Utility

\section{Introduction}

In discussions of energy for sustainable development, renewable energy and energy efficiency represent two important types of policy intervention. Unlike renewable energy (RE) programs (a supply-side intervention), energy efficiency (EE) tends to represent a form of demand-side management. Policymakers will set the targets and (often) procedures for EE initiatives. In general, the energy sector regulator will have a less direct role in $\mathrm{EE}$ than in $\mathrm{RE}$ initiatives, since the latter primarily involve adjustments by customers. However, EE basically promotes energy conservation, so energy efficiency programs impact utility revenues and costs (directly through changes in consumption and production patterns and in program costs). These impacts mean that the energy sector regulator is in the position of promoting or blocking some EE initiatives carried out by the electric utilities (Cicchetti, 2009). The survey examines the extent to which energy sector regulators in developing countries have the functional authority and capability to promote EE programs by utilities. Regulatory rules can create incentives for utility EE initiatives or create disincentives for such activities.

\footnotetext{
${ }^{1}$ Tel: +01 352392 0132; fax: +01 352-392-7796; E-mail address: sanford.berg@warrington.ufl.edu Public Utility Research Center, Warrington College of Business, University of Florida, Gainesville, FL 32607
} 
Delina (2012) provides an excellent overview of energy efficiency institutions, drawing upon the institutional models for energy efficiency implementation identified by the World Bank (2008). However, the study does not present an example of the first "model" - a government agency with broad energy-related activities. The purpose of this article is to fill that gap by outlining how functions of energy sector regulators can affect the scale and scope of EE programs implemented by electricity distribution utilities. Certainly the other institutional formats described by Delina (primarily different types of agencies focusing exclusively on funding $\mathrm{EE}$ ) have been important sources of initiatives (and money) that promote EE in developing countries. In addition, such agencies often provide (or require the provision) of information that consumers might act upon. However, energy sector regulators also have the three enabling features Delina identifies as essential for coherent institutional governance regarding EE: technical capacity (and authority to approve utility EE outlays), motivation (particularly in the context of excess demand for electricity), and tools for effective policy interventions (depending on the information available to and legal authority delegated to the regulator).

This overview of the potential role of sector regulators is not meant to advocate their greater engagement. Many regulators are reactive, rather than proactive-the agencies are often young and have severe budgetary constraints, limiting their ability to develop, implement, and evaluate programs. ${ }^{2}$ In addition, even if a distribution utility in a developing country shows some interest in energy efficiency, there may be other objectives that dominate the policy discussion: price, reliability, network coverage-to list a few. However, when there is rationing, the utility (and regulator) should be particularly interested in conservation, since such behavior on the part of consumers improves service quality. Whether a regulator in a developing country is in the best position to incentivize EE activities depends on the context.

Nevertheless, this author believes that policy-makers and energy scholars should be more aware of the tools available to energy sector regulators. These (relatively) young agencies have expertise, legitimacy with consumers, and credibility with those funding energy efficiency initiatives. They provide advice to national governments and are central to approving outlays by utilities. This article both draws attention to their capabilities and outlines important roles that could be activated more fully in the future. It is not meant to be a case study, but does introduce sustainability researchers to another institution that warrants attention. Sound regulatory governance is necessary (but not sufficient) for some types of EE initiatives to be successful. For example, Eskom's demand management programs in South Africa (launched in 2007) only apply to business customers-reflecting a concern that further expansion of the program would not be cost-effective.

Of course, policy-makers (legislators and government ministries) are the ones who establish goals and agencies related to $\mathrm{EE}$ (and renewable energy). These initiatives reflect broad public concerns regarding energy security, adequacy of supply, economic development, climate change, and public health. Energy sector regulatory commissions provide advice to ministries and legislators, but they also engage in rule-

\footnotetext{
${ }^{2}$ As pointed out in personal correspondence, Dutt took governmental initiatives in support of EE and load management by distribution companies in Argentina (1996-2002); however, he found that utilities were not interested in EE. When there is vertical disintegration, electricity can be a pass-through cost. In such situations, distribution companies have less incentive to engage in EE. Rather, other institutions in Argentina took leadership; for example, the sale of conventional incandescent lamps was eliminated and refrigerator labeling on EE was instituted.
} 
making related to utility-based programs affecting EE. Other agencies set appliance standards, provide government financial support, create tradable certificates, award tenders, and establish government programs, like improving EE in schools and hospitals. ${ }^{3}$ Thus, the sector regulator must also factor in the interdependencies among EE programs when determining the cost-effectiveness of utility-based programs. Such programs only add incrementally to the savings already achieved by other programs, so they should be evaluated in the context of other initiatives.

\section{Rationale for Intervention by the Energy Sector Regulator}

Even if public policy supports $E E$, one can ask why a utility would encourage energy efficiency that reduced the demand for its product. The potential lack of motivation implies that the sector regulator will find it difficult to establish programs that reduce utility cash-flows (while at the same time promoting the financial sustainability of utilities). However, in the case of developing countries, there are several reasons why managerial incentives might be aligned with those supporting conservation and energy efficiency. First, electricity is often underpriced in developing countries: if the revenue from a customer is less than the marginal cost of serving the customer (given that the distribution system is already built), then utility-based energy efficiency programs improve the financial viability of the utility. Second, system reliability is often low, with rolling black-outs or unpredictable voltage reductions: so $\mathrm{EE}$ programs potentially strengthen reliability-which, in turn, may improve public perceptions about the utility and increase citizen willingness to pay for the higher-quality service. Thus, EE can improve the profitability and operations of utilities in capacity-short developing countries.

A related issue is whether the sector regulator has confidence that utility funding of EE initiatives will be spent in a cost-effective manner. Unless funding comes from an external source, such as a government transfer, an NGO, or a multinational donor, the cost of EE programs must be borne by customers. The electricity sector regulator will be hesitant to approve expenditures on programs that do not clearly benefit existing customers. A contentious issue is the standard to be used for evaluating EE programs. There are at least five alternative tests to determine the costs and benefits of energy efficiency programs in the U.S.: all five tests taken together provide a comprehensive picture of a program's impact. ${ }^{4}$ However taken individually, they will provide different rankings of alternative programs. The regulatory tests include the following comparisons of benefits and costs:

(1) Participant cost test (will participants benefit over the measure's life?),

(2) Program administrator cost test (will utility bills increase?),

(3) Ratepayer impact measure (RIM test-will utility prices increase?),

(4) Total resource cost test (will the total costs of energy decrease?), and

(5) Societal cost test (is the utility, state or nation better off, including changes in environmental impacts?).

\footnotetext{
${ }^{3}$ Koskimäki (2012) describes lessons from the EU for sub-Saharan countries, focusing on energy-intensive products, buildings, transportation, and EE in cities. The role of the sector regulator is not emphasized.

${ }^{4}$ California Standard Practice Manual (2001). The IEA Energy Efficiency Governance Handbook goes into much more detail on the importance of having a coherent system for developing, incentivizing, and evaluating energy efficiency programs.
} 
Despite the analytical complexities in evaluating $\mathrm{EE}$, some attempt must be made to quantify impacts so that programs can be compared. In some countries, the test is specified by law; in others, it is up to the sector regulator to determine the appropriate test. ${ }^{5} \quad$ Ultimately, the primary test adopted for evaluating alternative programs will drive the net present value calculations for specific utility programs (assuming there is agreement on the appropriate discount rates to be used in the analysis). Determining the correct metrics depends on the objectives of the program. Standard finance tools provide key techniques for evaluating proposed programs as well as their impacts.

The Standard Practice Manual goes into detail regarding the formulas for the various tests. Whether particular impacts are "counted" or not affects whether a program will be viewed as cost-effective: the choice of a particular test (or combination of tests) by the regulator significantly affects the types of EE programs that can be implemented by the utility. Another issue is whether individual programs for particular customer groups (such as those using emerging technologies or those directed at the poor) need to pass the test, or whether a portfolio of projects should pass the test. Other indicators include the ratio of benefits to costs, internal rate of return, levelized cost of conserved energy, and the payback period. However, Net Present Value provides the most comprehensive measure for benefits and costs since it captures monetary inflows and outflows over time. Ultimately, part of the justification of EE programs is from the environmental benefits which can be difficult to quantify.

The best approach might be to use the methods that best address the focus of the policy and compare the results of the analysis. Ultimately, the regulatory ruling requires an analysis of the "no initiative" scenario (without the EE program), so the analysis considers differences from the baseline. As has been noted, that baseline must include EE initiatives being undertaken through non-utility programs. In addition to the internal consistency of the programs, regulators must be aware of the effects of interactions between these programs, as these interactions may change the impacts of individual programs or produce unintended consequences. Policy-makers and those affected by EE initiatives need to be aware of how regulatory functions and incentives affect the scope and effectiveness of utility-based EE initiatives.

\section{Policy Responses: Institutions Matter for Program Development and Implementation}

According to the United Nations Development Program, "Energy is central to sustainable development and poverty reduction efforts. . . . None of the Millennium Development Goals (MDGs) can be met without major improvement in the quality and quantity of energy services in developing countries." 6 However, promoting EE is much more than a technological or engineering task. Figure 1 depicts how public policy establishes regulatory functions and other programs (and institutions) that affect EE. Thus, in addition to agencies that focus on $\mathrm{EE}$, sector regulators have a role to play in promoting cost-effective

\footnotetext{
${ }^{5}$ Parthan et. al. (2010) evaluate EE and RE programs, noting the care that must be taken when evaluating programs and the governance issues that can arise in the implementation process. Holt and Galligan (2013) contrast EE approaches taken in the U.S. (decentralized) and E.U. (more centralized with specific carbon-reduction targets). See also ICER, 2010

${ }^{6}$ http://www.undp.org/content/undp/en/home/ourwork/environmentandenergy/focus areas/sustainableenergy.html
} 
EE (described in more detail in the next section). Utility programs related to EE include energy audits, pricing and billing practices, and consumption/loss reduction targets. The International Energy Agency's Energy Efficiency Handbook specifically identified energy providers (utilities) as having a role in implementing EE. Such activities call forth monitoring and rule-making activity by the sector regulator. The IEA identified the advantages and disadvantages of utility EE initiatives (p. 26):

\section{Advantages:}

- ready access to capital;

- an existing relationship with end users, including billing systems and market data;

- a familiar brand name;

- a widespread service and delivery network within their jurisdiction;

- responsible for anticipating and accommodating energy and peak demand growth.

\section{Disadvantages:}

- [low] overlap in commercial and societal interests;

- competitive disincentives to incur costs, increase prices or reduce sales.

In recognition of the strengths and limitations of having the utility deliver EE programs, policy-makers need to carefully evaluate the circumstances in their jurisdiction as well as the unique capabilities of their utilities. Furthermore, the electricity sector regulator often makes its expertise available to those developing and implementing EE policy. Ultimately, the sector regulator is responsible for providing oversight of electric utility activities. Thus, the energy regulator can incentivize utility-based EE actions such as the following initiatives (listed in Figure 1):

1. Conducting Energy Audits for Residential, Commercial/Industrial and Government Customers;

2. Regulating meters, billing, and other consumption information provided to consumers;

3. Reducing Consumption through conservation rates and Promoting improvements in Load Patterns and Power Factors through time of use pricing and demand side management (see Charles River Associates, 2005)

4. Regulating meters, billing, and other consumption information provided to consumers;;

5. Incentivizing improvements in System Reliability (reducing self-generation by larger customers);

6. Incentivizing utilities to reduce Line Losses (Pacudan and Guzman, 2002); and

7. Encouraging investments in smart grids (mainly for middle in high income countries)

These programs are not self-implementing, nor are they necessarily cost-effective (depending on the scale and scope of the program). So the sector regulator plays a role in monitoring and evaluating them-since utility resources are used in these programs. In particular, those resources could, instead, be applied to improving service quality or expanding access to the network.

Other agencies promote a variety of programs listed in Figure 1:

1. Subsidies and Tax Incentives

2. Public Information (Brounen, Kok, and Quigley, 2013)

3. Building Codes (Jiang, 2011; Thorsnes and Bishop, 2013)

4. Appliance Labeling and Industry Standards for Products using Electricity

5. Training Programs for technical workers (conservation and EE skills)

6. Demonstration Projects (that can then be scaled up)

7. Tradable Certificates/saving obligations on energy utilities (Langniss and Praetorius, 2004) 
8. Energy end-use efficiency in the public sector (for example, schools and hospitals)

9. Promotion of Energy Service Companies (ESCOs) that assist end-users in identifying, financing, and implementing energy savings projects.

The sector regulator is often in a position to give advice regarding these types of initiatives as well. In addition, these programs affect the additional benefits from expanded utility-based programs, so their impacts must be incorporated into the evaluation of utility initiatives. Figure 1 depicts the primary role of policy-makers in identifying and prioritizing objectives and establishing EE targets. Nevertheless, the sector regulator has a number of roles and responsibilities for operationalizing and implementing RE.

\section{[Insert Figure 1 about here]}

\section{Regulatory Functions related to Energy Efficiency}

Although energy sector regulators might serve in an advisory capacity in the evaluation of broad public policy towards EE programs, the focus here is on those activities most closely linked to regulatory functions. Particularly for a developing nation, where the agency has a limited track record in dealing with state-owned or privately owned utilities (Vagliasindi, 2008, p. 3), it will be important to identify the most cost-effective utility initiatives. Energy sector regulators often have authority to carry out functions that have implications for the financial feasibility (and effectiveness) of utility-based EE programs. Ten functions (identified in Berg, 2013) are listed below:

1. Issuing licenses related to regulatory functions: Certifying and licensing those who perform $\mathrm{EE}$ audits could be one task performed by the energy sector regulator; however, another agency could also perform this function. Licensing is less important for EE than for renewable energy since only the latter involve siting issues and (potential) approval of specific generating technologies.

2. Setting performance standards: If any performance targets are established for $E E$ (for reducing energy consumption), these would be determined by broad public policy, leaving the sector regulator to implement incentives that contributed to the achievement of these targets. Significant regulatory attention would be devoted to the cost-effectiveness of programs under the control of utilities. The particular test employed would depend on the scope and priorities of the EE policy established by political actors, but it is likely that one measure alone will not provide a definitive answer for regulators.

3. Monitoring the performance of regulated firms: An important task for regulators is to ensure that contracts with external service providers are properly designed and bid. As with RE, evaluating EE programs requires data collection and analysis. Reviewing the impacts of previous programs is crucial if decision-makers are to benefit from the lessons of the past. When unintended consequences of actions begin to be noted, the policies should come under immediate review. In addition, the impacts can be different, depending on utility ownership. For example, a Ukrainian regulatory incentive to reduce line losses improved the performance of privately-owned utilities but not publically-owned utilities (Berg, et. al., 2005). 
4. Establishing the price level and the structure of tariffs: When a customer makes an energy efficiency investment, quantity demanded is reduced-lowering the utility bill, reducing utility revenues, and improving reliability (assuming minimal rebound effect due to customers obtaining the services of electricity intensive appliances at lower cost). Forecasting the extent of the consumption reduction requires estimates of behavioral change. If the utility subsidizes the investment, regulators will need to analyze, evaluate, and approve utility-based programs using tests described earlier. In addition, EE can be promoted by particular rate designs, including time of use rates and industrial customer penalties for low power factors.

5. Establishing a Uniform Accounting System: Without clear definitions and consistent categories, analysts cannot observe trends over time. Evaluating the cost-effectiveness of EE initiatives requires that operators provide data and reports and that regulators have the technical capacity to review those studies. Unless the law specifies the test, the regulator must determine which benefit-cost test should be applied to utility programs. Program cost recovery will be an important determinant of managerial support for utility EE initiatives.

6. Arbitrating disputes among stakeholders: Regulators can help resolve issues that are technical in nature; for example, which benefit-cost test to use for evaluating EE programs. Different customer classes will object to cross subsidization caused by utility programs. The regulatory commission is in a position to organize workshops, educate stakeholders, and promote dispute resolution.

7. Performing (usually via independent consultancy) management audits on regulated firms: The regulator should review the organizational elements of EE programs on a regular basis to ensure efficiency: are the goals of EE programs being met in a cost-effective manner? In addition, is there a portfolio of programs ensuring that all customer groups are able to participate in EE initiatives? Developing comprehensive contracts and verifying performance (by the utility or an Energy Service Company) are two fundamental tasks for the regulator.

8. Developing human resources for the regulatory commission: The implementation of EE policies depends on the quality of the professionals who are conducting regulatory analyses. This function requires that the agency maintain a strong capacity-building program, so members of the professional staff are trained to conduct necessary analyses and provide oversight for utility programs. Similarly, in the case of "white certificates", the baseline for an EE improvement needs to be established, and techniques for measuring energy savings need to be developed. ${ }^{7}$ The regulatory

\footnotetext{
${ }^{7}$ Also known as White Certificates and Energy Efficiency Credits (EECs), EECs certify the attainment of a certain decrease in energy consumption. These targets imply reductions from some baseline (actual or predicted). Italy, France, and Denmark (in 2005-2006) initiated programs whereby producers or distributors implemented $\mathrm{EE} /$ conservation projects that reduced energy consumption. If target are not met, there are penalties. The introduction of tradability promotes the least-cost achievement of targets and should stimulate activities by Energy Service Companies (ESCOs). However, Energy Efficiency Certificate programs can involve substantial set-up and transaction costs (developing the system, determining a baseline, and authenticating savings).
} 
commission could have a role in both areas-requiring staff with technical skills (Langniss and Praetorius, 2004). If another agency is delegated the responsibility for designing the certificate market, the energy sector regulator still would need to monitor such programs.

9. Coordinating Decisions with Other Agencies: Ministries of Energy, the Environment, Finance, and others have an interest in utility EE initiatives. To ensure that the interdependencies among utilitybased and other EE programs are recognized by policy-makers, the energy regulator has a responsibility to participate in Task Forces and other collaborative activities.

10. Reporting sector and commission activities to appropriate government authorities: Given the expertise assembled at a commission, the agency can provide information and advice to appropriate government departments that are concerned with EE.

The functions (also listed in Figure 1) illustrate how the roles and responsibilities of energy sector regulators place them in a position where their advice, rule-making, and performance evaluations affect how and what utilities will do in the area of EE. As noted by Sarkar and Singh (2010), regulators make decisions that affect the funding and success of EE investments: their study underscores the importance of balancing regulatory/enforcement regimes and incentives and suggest that the role of sector regulators warrants greater attention by policy analysts.

\section{Challenges in Developing and Implementing Cost-Effective EE Policies}

As has been shown above, broad public policy determines whether EE governance results in programs that are consistent with one another; without consistency and clear mechanisms for accountability, the system of institutional responsibilities will lack coherence. The reader is referred to a report by the International Confederation of Energy Regulators: A Description of Current Regulatory Practices for the Promotion of Energy Efficiency (2010) for specific country cases. Here the focus is on the role of the sector regulator in providing oversight for utility-based EE initiatives-particularly on the challenges faced by the regulator (listed in Figure 1). The following steps can help sector regulators address the types of problems that tend to arise when regulators become involved in promoting energy efficiency.

Develop Regulatory Expertise: Technical capacity is essential if the sector regulator is to be in a position to monitor and evaluate utility-based EE programs. Without a deep understanding of the benefits and costs of different EE strategies, the regulator is not in a position to incentivize and evaluate programs. With expertise, rules are more likely to be predictable (since they are evidence-based) and transparent (since the analytic techniques and procedures reflect best practice). An agency needs to be consistent in both its process and in the substance of its decisions. Of course, sound decisions require excellent support staff. To recruit and retain talented professionals requires salaries commensurate with the job requirements. Capacity building is essential if support staffs are to have technical skills and motivation to develop evidence-based recommendations. The most dangerous "knowledge" is a principle or idea that is actually false. All of us are susceptible to excessive confidence in our own understanding of the way things work. That is one reason why open discussions among stakeholders are necessary within any 
system. When conflicting ideas are not openly discussed, decisions are likely to be based on inaccurate information and/or inappropriate methodologies. In the case of EE, multiple disciplines (including engineering, economics, finance, accounting, law, communications, management and other fields) are necessary to bring a wide range of perspectives on proposed initiatives.

Limit Information Asymmetries: Managers know far more than regulators regarding the ease or difficulty of implementing alternative EE strategies and improving performance. Regulators need to devise mechanisms that cause firms to reveal information so the choice of strategies is based on solid data. Access to information regarding the timing (and incidence) of the costs and benefits of utilitybased initiatives is necessary for sound regulatory decision-making. Drawing upon the experience of EE initiatives in neighboring countries is one way to gain fresh perspectives on setting reasonable targets (such as the number of energy audits and associated consumption impacts) and devising incentives that promote efficiency in EE programs. As Ralph Waldo Emerson said, "People only see what they are prepared to see." Past experiences (and ideological predispositions) place blinders on us. Researchers call this confirmatory bias. We tend to discount or misinterpret facts that are inconsistent with our own world view. Cases from other nations remind us that we all wear blinders and need to interact with others to better understand what might be most effective in the local setting. Learning from counterparts around the world represents one way to strengthen decision-making, while at the same time the sharing of information reduces information asymmetries. ${ }^{8}$

Promote Public Participation: Citizen Engagement in the EE process represents an important source of information and a forum for educating key groups. Hearings provide one format for obtaining opinions - though the weight given to concerns and expressed desires will depend on the extent to which the positions are grounded in reality. The public is seldom fully aware of current infrastructure policies and rules, so stakeholder participation is a key feature of commission procedures that promotes public understanding. For developing countries, bills to residential customers represent the primary communication channel to this group-so it becomes important that utilities design a format and select information and effective messages that are consistent with education levels and cultural norms. Transparency implies clear regulatory rules and behavior that give citizens (including utility managers) confidence in the professionalism of those providing sector oversight. If the regulatory process is transparent, stakeholders (including political leaders) will understand the rationale behind decisions, and will be in a position to follow-up on the impacts of regulatory rules.

Utilize Processes that Create Legitimacy for Rules: In addition to public participation, regulators and managers must devote resources to educating the public. The menu of options and rationale behind EE programs both need to be communicated to stakeholders. It is said that "the fewer the facts, the stronger the opinion." While good stewardship of our resources would seem to be uncontroversial, the choice of specific policies and rules is bound to have differential impacts on different stakeholders. It is easy for policy-makers to endorse a program with strong rhetoric, but they often ignore the question of who will pay for the initiative. One way to reduce the divisive role of rhetoric is to introduce

\footnotetext{
${ }^{8}$ Regional regulatory associations can act as clearinghouses for studies and reports. They promote capacity building through conferences and technical workshops (Berg and Horrall, 2008).
} 
information about the costs and benefits of different EE options, making clear both the short and long term impacts of EE. If the educational process is effective, stakeholders (including political leaders) will understand regulatory decisions. Ideally, regulatory systems should promote credibility (with investors and government funding sources), legitimacy (so consumers feel protected from monopoly prices and from poor service), transparency (so participants know the rationale for decisions), and efficiency in the delivery of service (so valuable resources are not wasted through mismanagement or political interference). For example, in Egypt, one load shedding agreement for $160 \mathrm{MW}$ is in place between the Transmission System Operator and a large fertilizer company. The Egyptian regulatory authority is preparing a regulatory framework for interruptible contracts, including rules for load shifting, peak shaving, planning of regular and annual maintenance. (ICER p. 142).

Avoid Policy Shifts and Unclear Objectives: Lack of consistency in energy policy creates uncertainty for consumers and for managers, and raises the cost of capital for utilities. Similarly, those developing and implementing policy need to prioritize objectives. Since there are many potential policy objectives, not all can be given equal weight. Selecting the appropriate level and mix of EE initiatives is just one of the many issues energy decision-makers face in developing nations: other sector problems include line losses (reflecting system design and theft), collections, network coverage, service quality, affordability, and cost-containment. The weights given each of these issues depend on current levels of sector performance, tools available to the regulator, and citizen attitudes. Regulators need to work with stakeholders to educate those affected by price, quality, and network coverage. Since infrastructure is so important for economic growth and social cohesion, public policy generally attempts to promote network expansion. The sector requires significant capital investments, so decision-makers need to prioritize their objectives and carefully define the problems they face. Companies, ministries, and regulators all shape the way issues are defined and addressed in the regulatory process. The key point here is that EE may not be the highest priority objective for some nations, but foundations can still be laid for such programs (in terms of capacity-building, data collection, public education, and careful sequencing of new initiatives.

Develop Adjustment Mechanisms: Regulators gather information through the adjudication of specific rate cases (via formal hearings or all-party-settlements) and rule-making (for addressing emerging sector issues). These processes enable regulators to make decisions regarding both utility cases and broader sets of problems facing policy-makers. Basically, programs need to have predictable funding and have processes that enable fine-tuning (including the development of exit-strategies). Regulators should have the analytical skills required for evaluating and adapting programs over time as new information emerges. Thus, for hearings and workshops, schedules for the hearing process need to be developed, disseminated and adhered to: delays have differential impacts on different stakeholders. Brennan and Palmer (2013) provide advice to policy makers developing energy efficiency resource standards and programs: their Table 1 contains a list of justifications for intervention, with a focus on how programs need to be adjusted as new information is obtain and objectives are re-prioritized.

Create Templates for Program Evaluation: The utilization of appropriate evaluation methodologies requires that data be defined, collected, and stored in consistent frameworks. The five EE benefit-cost tests described earlier utilize sub-sets of information associated with particular EE initiatives, so a 
template for program evaluation is essential if the comparisons are to be consistent across EE options. Thus, potential initiatives need to be compared across different types of programs; also, clear bidding processes are needed to ensure that political cronyism does not drive the selection of contractors. In addition, uncertainties for different program outcomes need to be incorporated into the framework so discount rates are to reflect the respective risks associated with the different options. Of course, with experience (and investments in learning from the experiences of others), those uncertainties will be reduced. Challenges associated with this issue are somewhat alleviated through a uniform system of accounts and parallel information on operations and behavioral responses. In Brazil, the national energy regulator, ANEEL, has a specific energy efficiency department that is in charge of the assessment and approval of utility EE programs. The basic evaluation framework is developed by the Energy and Mines Ministry, and the resulting Federal Energy Efficiency Programs are implemented by Petrobras and Electrobras.

Limit Inter-Agency Conflicts: A number of governmental entities will have an interest in the funding and success of EE programs, such as the Ministries of Finance, Environment, and Industrial Development. Disputes over who has authority (or the final say) regarding programs reduce the likelihood that effective programs will have the support of key stakeholders. Regulatory incentives and rules need to have broad political support; in addition, the process should give clear decision-authority to specific institutions. Thus, regulators and operators need professionals with leadership skills, experience in negotiation, and proficiency in communication. Regulators often serve as mediators when complex issues arise regarding EE. These agencies often have expertise lacking in other branches of government. Regulatory reports and public meetings provide platforms for identifying issues and the implications of alternative approaches to resolving issues associated with EE. Technical skills are necessary but not sufficient for strong sector performance. Soft skills related to communication and conflict resolution are also necessary.

Promote Evidence-based Benefit-Cost Analyses: Political promises often establish unrealistic citizen expectations: the result is disappointment for all stakeholders, including elected officials. Regulators can contribute to cost-effective EE by requiring that decisions be data-driven, not driven by ideology or political posturing. Particularly in resource-strapped developing nations, promoting EE requires both regulators and distribution utilities to have the capacity to analyze alternatives and to implement selected programs in a manner that involves clear accountability and regular evaluations. An evidencebased approach tends to yield more efficient arrangements for infrastructure service delivery, grounding in reality the expectation of policy-makers and the general citizenry. For example, in Jamaica, JPS (the electricity supplier) had several areas of Kingston with significant demands but few paying customers. Commercial losses (through illegal and unsafe connections) were substantial. After a major initiative (involving local government and the community), poor families were safely connected to the grid and overall consumption fell. Some of that drop can be attributed to conservation activities of households and some due to inability to afford the quantity that had been previously consumed at a zero price. Jamaica's Office of Utility Regulation encouraged and provided oversight of the process - which had a payback period of less than two years. ${ }^{9}$

\footnotetext{
${ }^{9}$ This case was presented at the PURC/World Bank International Training Program of Utility Regulation and Strategy, based on work by Damian Obiglio.
} 
Avoid Special Interests that Back Specific Programs: The economic theory of regulation suggests that when legislators (or regulators) consider implementing new rules, those who stand to gain from the particular rule tended to be few and concentrated; they are well aware of the benefits and will devote resources to lobbying for the rule (Peltzman, 1976-expanding on Stigler's seminal contributions). On the other hand, a larger number of individuals tend to bear the costs, but the per capita cost is small relative to the per-capita benefit to those who gain from the rule. These individuals (customers, for example) are less likely to be organized in opposition to the rule. Such rules might be adopted even when the total benefits are less than the total costs. This point also applies to EE initiatives, so care must be taken to limit the likelihood that special interests dominate both the legislative and rule-making processes.

\section{Conclusions and Policy Implications}

The rationale behind regulatory support for utility-based EE initiatives is that market failures justify government playing a role in promoting EE. However, there is also the possibility of government failures, as when particular initiatives or technologies are favored as a result of special interest lobbying. In such cases, economists have argued that sector regulation might benefit one set of stakeholders at the expense of other stakeholders (such as diffuse sets of utility customers); this raises questions of fairness. In addition, the benefits might not exceed the costs of particular EE initiatives; this possibility raises the question of efficiency. The sector regulator must be sensitive to the possibility of regulatory capture: its rulings may benefit groups that are highly organized and stand to benefit from particular utility-based programs, while unorganized (generally diffuse) groups bear the cost burdens. ${ }^{10}$ In such cases, the benefits may not outweigh the costs of EE programs. Of course, calculating the benefits of environmental impacts is particularly difficult. Thus, the sector regulator has a role as advocate for customers-balancing the interests of today's customers with those of future customers. EE programs have costs that must be covered by today's customers, future customers (via interest payments on bonds), donors, or taxpayers. For the vulnerable, poor, and politically powerless, service delayed is service denied.

In some ways, utilities can be very effective promoters of EE: they are in a position to analyze bills and conduct on premise energy audits to identify areas of saving. Depending on the EE law, regulators could require utilities to undertake costly audit programs; the savings on electricity bills could be shared with the utility-until the audit outlays are recovered. If the audit leads to customer outlays, then customer costs also need to be recovered in the sharing plan for allocating bill savings from investments. ${ }^{11}$ The

\footnotetext{
${ }^{10}$ Regulatory capture is not necessarily due to being "bought off" by special interest groups. Rather, if key regulatory decision-makers mainly interact with the utility or with program beneficiaries, the decision-makers can begin to identify with the entities they are supposed to regulate or with groups that are well-represented at regulatory hearing. In such situations, regulators are less able to be umpires who are advocates of both efficiency and fairness.

11 "Energy audit allows a systematic approach for decision-making in the area of energy management and represents an effective tool in defining and pursuing comprehensive energy management program. Audits are scalable, and can be applied to large and small users, domestic and business. Audits consists of the verification, monitoring and analysis of energy use, including submission of technical reports containing recommendations for improving energy efficiency, based on cost-benefit analysis, and an action plan to implement them. The audit is aimed at identifying all of the energy streams present in a facility and quantifying energy usage according to its
} 
long term impact of effective programs is to delay the construction of new generating units. However, for a utility that is not rationing electricity, if price is greater than marginal operating cost, demand reductions represent lost net revenue. Regulators need to recognize the potential conflicts that can arise from such outcomes. Thus, the energy audit process could be outsourced to Energy Service Companies (ESCOs). Palmer et al. (2013) emphasize that competing entrepreneurs in the provision of EE services may be more likely to develop innovative, least-cost approaches to EE. Utility-based programs could "crowd out" more effective programs: " . . having utilities play a lead role allows state legislatures to propose and endorse energy conservation policies but to shift to state regulatory commissions the responsibility for funding them through electricity rate increases. This allows the legislature to avoid the political fallout from raising general taxes to pay for these programs." (p. 53)

Strategies for promoting EE can improve system operations and are central to an electricity regulator's mission to improve sector performance. However, the regulator must be certain of the costeffectiveness of utility-based EE-initiatives, since (for developing countries) those funds could be applied to expanding the distribution network in urban and peri-urban areas, or promoting access in rural areas. State-owned and privately-owned utilities may place different weights on the bottom line (or the return on investment), but managers for both types of service providers will need to be brought into discussions of alternative EE programs early in the process. Of course, regulators need to ask whether the utilities they are monitoring have the capacity to successfully implement EE programs and projects. If utilities have little experience in the field, then "starting small" makes sense, so that the utility's capacity to implement programs grows over time.

Note that the State might develop grants, subsidies and tax incentives for energy efficiency investments, but these are not generally instruments available to regulators. Similarly, public information campaigns, adding EE to school curricula, developing appliance labeling systems, and creating certification programs for buildings are outside typical responsibilities for energy regulators.

Ultimately, public policy will determine broad approaches to energy efficiency. However, initiatives undertaken by the utility must generally be approved and certainly be monitored by the regulator, since these initiatives have implications for cost and demand patterns (and therefore, the price level and average price). EE and conservation programs incentivized by the utility must be approved and monitored by the regulator to ensure that the programs are well-designed and that they meet the objectives of the enabling legislation. The role of regulators also involves providing technical input into the development of EE policies initiated by other agencies or via legislated tax programs. Formal memorandums of understanding should be developed with entities promoting $E E$, such as the Energy Ministry and environmental agencies. Such MOUs need to specify the responsibilities of the different entities so as to avoid duplication of effort (reducing delays) and to limit the likelihood that some problems will not be addressed. It also should be noted that the ability to devote resources to EE depends on the nation's income level, so the availability of external funds is often another driver of demand-side EE policies.

discrete functions. The audit facilitates subsequent measures that can be undertaken, including the reduction of energy consumption, fuel switching, and load management." ICER pg. 32 
Achieving consistency across utility-based EE initiatives and EE programs implemented by other groups is no easy task. Given the many burdens of (and small budgets for) newly established regulatory commissions, simplicity and scaling up over time are probably the two key words that characterize bestpractice. Nations have a wide range of options for addressing EE issues. It is up to the sector regulator to provide input into the policy-making process and then to implement national policies in ways that clearly improve sector performance and promote financial and environmental sustainability.

\section{Acknowledgements:}

The author gratefully acknowledges the research assistance of Achala Acharya. Ted Kury, Fernando Prado, Lynne Holt, Gautam Dutt, and unidentified reviewers provided helpful comments on earlier drafts. Participants in the PURC/World Bank International Training Program on Utility Regulation and Strategy have contributed to the author's understanding of the strengths and limitations of sector regulators in addressing challenging issues like energy efficiency initiatives by utilities. Remaining errors are the author's alone. Funding from the Norwegian Trust (through the World Bank) is gratefully acknowledged. Greater detail on the points developed here is available at http://regulationbodyofknowledge.org/renewable-energy-and-energy-efficiency/. The reader is also alerted to a companion article (Berg, 2013) that focuses on the role of the electricity sector regulator in promoting or hindering renewable energy initiatives.

\section{References:}

Berg, Sanford (2013) "Regulatory Functions Affecting Renewable Energy in Developing Countries," The Electricity Journal, Volume 26, Issue 6, July, 28-38.

, Chen Lin and Valeriy Tsaplin (2005). "Regulation of State-Owned and Privatized Utilities:

Ukraine Electricity Distribution Company Performance," Journal of Regulatory Economics, Vol. 28, No. 3, 259-287.

and Jacqueline Horrall (2008). "Networks of Regulatory Agencies as Transnational Public Goods: Improving Infrastructure Performance," Review of International Organizations, Vol. 3, No. 2, June, 179200.

Brennan, Timothy J. and Karen L. Palmer (2013). "Energy efficiency resource standards: Economics and Policy," Utilities Policy, Vol. 25, June, 58-68.

Brounen, Dirk, Nils Kok, and John M. Quigley (2013). “Energy literacy, awareness, and conservation behavior of residential households," Energy Economics, 38, 42-50.

Cicchetti, Charles J. (2009). Going Green and Getting Regulation Right: A Primer for Energy Efficiency, Public Utilities Reports, Inc. Vienna, Virginia, viii-310.

Delina, Laurence L. (2012). "Coherence in energy efficiency governance," Energy for Sustainable Development, Vol. 16, December, 493-499. 
Energy Efficiency Governance Handbook (2010). International Energy Agency, 1-

52. http://www.iea.org/publications/freepublications/publication/gov handbook-1.pdf

ESMAP (2012) Energy Efficient Cities Initiative: Good Practices in City Energy Efficiency-Cape Town-

Kuyasa Settlement, South Africa. January. 1-14.

California Standard Practice Manual: Economic Analysis of Demand-Side Programs and Projects, (2001). http://www.energy.ca.gov/greenbuilding/documents/background/07-

J CPUC STANDARD PRACTICE MANUAL.PDF

Charles River Associates (2005). "Primer on Demand-Side Management: with an emphasis on priceresponsive programs," prepared for the World Bank, February, 1-

71. http://siteresources.worldbank.org/INTENERGY/Resources/PrimeronDemand-SideManagement.pdf

Holt, Lynne and Mary Galligan (2013). "Energy Efficiency Policies as Part of Carbon Reduction Efforts: Lessons from the EU for the U.S.," The Electricity Journal, Vol. 27, Issue 7, September, 33-42.

IEA Energy Efficiency Governance Handbook

(2010). http://www.iea.org/publications/freepublications/publication/gov handbook-1.pdf

International Confederation of Energy Regulators, ICER (2010). A Description of Current Regulatory

Practices for the Promotion of Energy Efficiency, June 21, Ref. I10-CC-02-04 (pdf) 1-176.

Jiang, Ping (2011). "Analysis of national and local energy-efficiency design standards in the public building sector in China," Energy for Sustainable Development, 15, 443-450.

Koskimäki, Pirjo-Liisa (2012). "Africa could take a leap to energy efficiency: What lessons could SubSaharan countries learn from European energy efficiency policy implementation?" Energy for Sustainable Development, 16, 189-196.

Langniss, Ole and Barbara Praetorius (2004). "How much market do market-based instruments create? An analysis for the case of 'white' certificates," Discussion Paper 425, German Institute for Economic Research, 1-25

Limaye, D. R., Heffner, and Sarkar, (2008), An Analytical Compendium of Institutional Frameworks for Energy Efficiency Implementation, Energy Sector Management Assistance Program (ESMAP) Formal Report 331/08, October, www.indiaenvironmentportal.org.in/files/EE Institutional.pdf.

Pacudan, Romeo and Elaine de Guzman (2002. "Impact of energy efficiency policy to productive efficiency of electricity distribution industry in the Philippines," Energy Economics, 24, 41-54.

Palmer, Karen L., et. al. (2013) "Putting a floor on energy savings: Comparing state energy efficiency resource standards," Utilities Policy, Vol. 25. 43-57. 
Parthan, Binu, Marianne Oskerkorn, Matthew Kennedy, St. John Hoskyns, Morgan Bazilian, and Pradeep Monga (2010). "Lessons for low-carbon energy transition: Experience from the Renewable Energy and Energy Efficiency Partnership (REEEP)," Energy for Sustainable Development, 14, 83-93.

Peltzman, Sam (1976). “Towards a More General Theory of Regulation,” Journal of Law and Economics, 19, 211-40.

Sarkar A. and J. Singh (2010), "Financing Energy Efficiency in Developing Countries-Lessons Learned and Remaining Challenges", Energy Policy. 5560-5571.

Taylor, Robert P., Chandrasekar Govindarajalu, Jeremy Levin, Anke S. Meyer, and William A. Ward (2008). Financing Energy Efficiency: Lessons from Brazil, China, India and Beyond. The World Bank 2008.

Thorsnes, Paul and Tim Bishop (2013). "The value of basic building code insulation," Energy Economics, $37,68-81$.

Vagliasindi, Maria (2008). "Governance Arrangements for State-Owned Enterprises", Policy Research Working Paper, $\mathrm{N}^{\circ}$ 4542, World Bank, Washington, D.C.

World Bank (2008). An analytical compendium of institutional frameworks for energy efficiency implementation. Washington, DC: The World Bank Group. 


\section{Figure 1 Regulatory Functions Influencing Energy Efficiency}

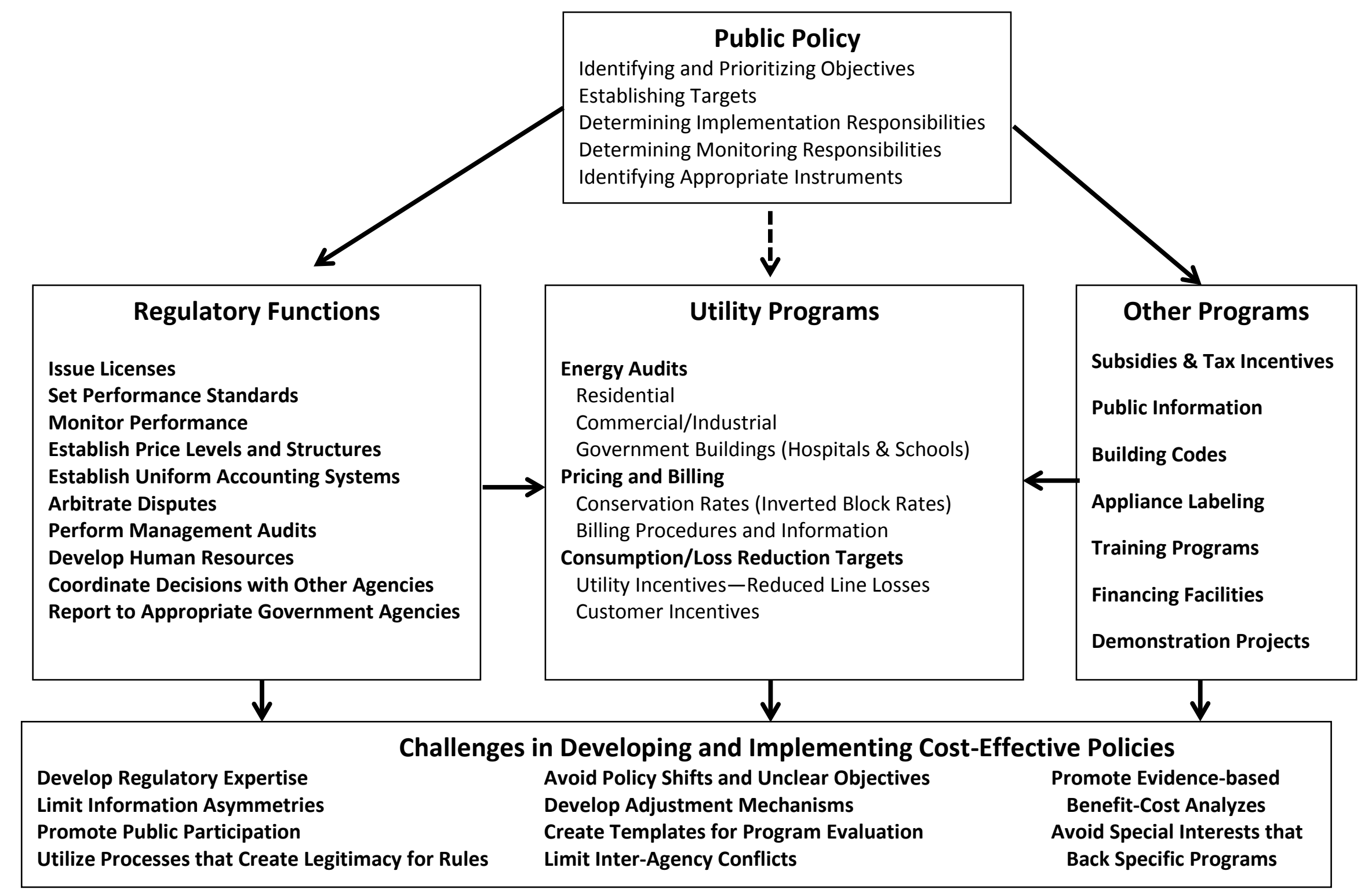

